\title{
BM Global Health How much does it cost to scale up surgical systems in low-income and middle-income countries?
}

\author{
Desmond T. Jumbam, ${ }^{01,2}$ Ché Len Reddy, ${ }^{1,2}$ Lina Roa, ${ }^{1,3}$ John G. Meara ${ }^{1,2}$
}

To cite: Jumbam DT, Reddy CL, Roa L, et al. How much does it cost to scale up surgical systems in lowincome and middle-income countries?BMJ Global Health 2019;4:e001779. doi:10.1136/ bmjgh-2019-001779

Handling editor Seye Abimbola

Received 17 June 2019

Revised 9 July 2019

Accepted 12 July 2019
Check for updates

(C) Author(s) (or their employer(s)) 2019. Re-use permitted under CC BY-NC. No commercial re-use. See rights and permissions. Published by BMJ.

${ }^{1}$ Program in Global Surgery and Social Change, Department of Global Health and Social Medicine, Harvard Medical School, Boston, Massachusetts, USA

${ }^{2}$ Department of Plastic and Oral Surgery, Boston Children's Hospital, Boston, Massachusetts, USA ${ }^{3}$ Department of Obstetrics and Gynecology, University of Alberta, Edmonton, Alberta, Canada

Correspondence to Mr Desmond T. Jumbam; desmond.jumbam@gmail.com
Poor access to safe, affordable and timely surgical, obstetric and anaesthesia (SOA) care remains a major cause of global morbidity and mortality, impacting low-income and middle-income countries (LMICs) most severely. Globally, approximately five billion people lack access to safe, affordable and timely SOA care. This accounts for about a third of the global burden of disease and drives close to 81 million people into catastrophic expenditure each year. ${ }^{1}$ In 2010, an estimated 16.9 million deaths worldwide, a third of all deaths, were attributable to surgical conditions. ${ }^{12}$ Annually, about 77.2 million disability-adjusted life years in LMICs could be averted with investments in basic, life-saving high quality SOA care. ${ }^{3}$

A major impediment to scaling surgical systems in resource-limited settings has been the notion that the cost is too high and the planning and orchestration too complex. SOA care systems require a functioning operating theatre along with specialised workforce, nurses, biomedical engineers, reliable supply chain systems for consumables and medicines, dependable blood banks, diagnostics, strong prehospital and referral systems and postoperative care. As Farmer and Kim succinctly put it, "there is no surgical equivalent to a vaccination campaign or a mosquito net". 4 This apparent complexity and the associated costs have made policy-makers reticent to invest in surgical systems, despite the need for these services to achieve the Sustainable Development Goals (SDG) and Universal Health Coverage (UHC). ${ }^{5}$

Since 2015, notable progress has been made at both global and national levels. At the global level, surgical and anaesthesia care has been explicitly acknowledged as an essential component of UHC by all Member States of the World Health Assembly through Resolution 68.15. ${ }^{6}$ This commitment was recently re-emphasised in a recent address by
Dr Tedros Adhanom Ghebreyesus, Director General of the WHO, who stated that "no country can achieve universal health coverage unless its people have access to safe, timely and affordable surgical services". 7 At the national level, countries around the world recognise that UHC and eight of the SDGs will not be achieved without intentional and systematic strengthening of health systems capacity to deliver SOA services. ${ }^{5}$ Countries are addressing these surgical inequity gaps through the development of National Surgical, Obstetric and Anaesthesia Plans (NSOAPs). These strategic plans recommended by The Lancet Commission on Global Surgery (LCoGS) in 2015 are created to systematically scale up SOA services within each country's national health strategic plan to improve health system outcomes while ensuring accountability and sustainability.

As part of the LCoGS, Verguet and colleagues estimated that scaling up surgical systems in LMICs to meet the target of 5000 surgical procedures per 100000 population would cost between US $\$ 300$ and 420 billion between 2012 and $2030 .^{8}$ Their costs were modelled based on both historical and aspirational rates of scale-up, given the baseline estimates of annual surgical volume in each country and number of operating theatres.

Since 2015, several countries have created and begun implementing NSOAPs, with over a dozen more NSOAPs in development (figure 1). Countries with fully-developed NSOAPs include Senegal, Zambia, Tanzania, Ethiopia, Rwanda and Nigeria. All of these plans have been fully costed, except Ethiopia and Senegal, which were developed before LCoGS. A review of the cost estimates associated with these NSOAPs reveal important insights into the scale of additional financial investments needed to strengthen surgical systems in LMICs. 


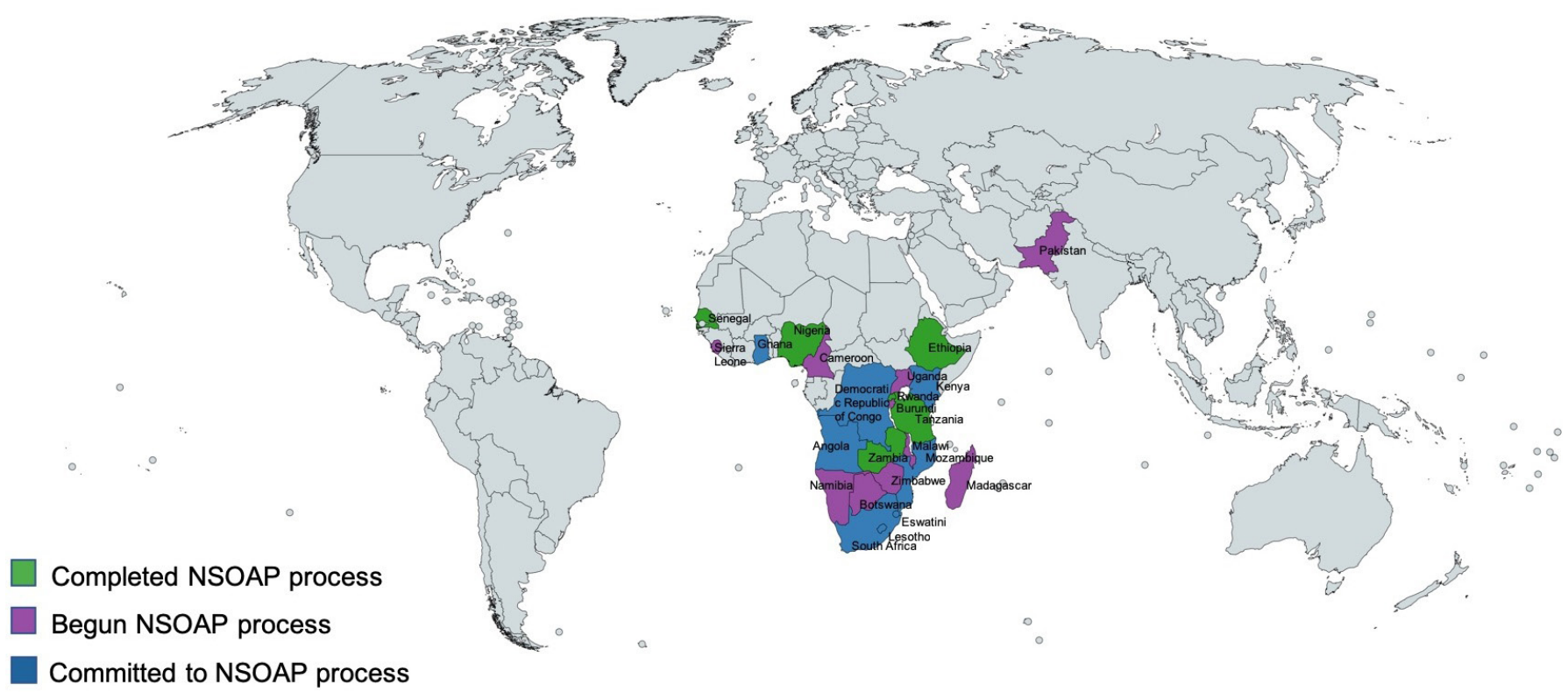

Committed to NSOAP process

Figure 1 Map of countries at different stages of the National Surgical, Obstetric and Anaesthesia Plan (NSOAP) process.

Table 1 summarises the investments in US dollars anticipated in the four countries with fully costed NSOAPs. The cumulative cost of implementation ranges from US $\$ 69.7$ million in Rwanda for a population of 12.3 million people to US $\$ 16.8$ billion in Nigeria for a population of 195.9 million people. Tanzania and Zambia fall in the middle with a cost of US $\$ 597.0$ million for 56.3 million people and US $\$ 314.2$ million for 17.3 million people, respectively. On a per capita basis, this represents US $\$ 0.94$ per person per year in Rwanda, US\$1.51 per person per year in Tanzania, US\$3.62 per person per year in Zambia and Nigeria estimated $\$ 17.12$ per person per year. Variations in costs between countries appear to be due to differences in NSOAP priorities set by each country. For example, in Nigeria, healthcare financing, which includes increasing health insurance coverage from $5 \%$ to $50 \%$ by 2023 , accounts for $56 \%$ of their NSOAP cost while the finance domain only accounts for $0.14 \%$ of Rwanda's NSOAP cost. Significant differences in NSOAP costs between countries could also be due to differences in costs of interventions between countries as well as the costing methodology used.

In terms of gross domestic product (GDP) per capita, Rwanda and Tanzania would need to invest approximately $0.13 \%$ and $0.16 \%$ of their current GDP per capita, respectively, to fully implement their NSOAPs. The Zambian NSOAP accounts for about $0.24 \%$ of their GDP per capita while Nigeria's account for about $0.87 \%$ of their GDP per capita. Countries considering investing in SOA care should take into account the cost of scale-up and should equally consider the economic consequences of failing to do so. As highlighted by Alkire and colleagues, LMICs stand to lose up to US\$12.3 trillion or $2 \%$ of projected annual GDP growth in middle-income countries by 2030 if they fail to invest in $\mathrm{SOA}^{9}{ }^{9}$ The economic consequences of surgically-avertable mortality and morbidity, especially as countries seek to increase human capital, cannot be overlooked, particularly with the epidemiological and demographic shifts in LMICs. For example, in the WHO Africa Region, non-communicable diseases and injuries account for about $47 \%$ of productivity losses as of $2015 .{ }^{10}$ Modest investments between $0.13 \%$ and $0.87 \%$ of GDP per capita to fund NSOAPs could prevent these large economic losses, in addition to the benefits of decreased morbidity and mortality from surgical conditions. Improvement of SOA care will lead to economic growth and should be considered a worthwhile investment for LMICs.

Systematically scaling up surgical systems appears to be affordable for the countries with NSOAPs. Fiscal space expansion for NSOAPs may in fact be possible from a variety of sources including increasing government health spending to reach national and regional health budget commitments such as the Abuja declaration. Currently, none of the countries with NSOAPs have met the target of the 2001 Abuja declaration, in which African heads of state pledged to set a target of allocating $15 \%$ of their annual budget to the health sector. ${ }^{11}$ Increasing the annual health budget to meet this commitment will provide significant resources to implement NSOAPs and improve SOA outcomes.

Health spending is expected to increase over the next decade as a result of GDP growth, government spending and government health spending. ${ }^{12}$ In lower-middle-income and upper-middle-income countries, health spending is expected to grow at an annual rate of $4.2 \%$ and $5.3 \%$, respectively. ${ }^{12}$ Growth in health spending will be much slower in low-income countries at a rate of $1.8 \%$. While it is possible that many LMICs have enough fiscal space in their annual budgets to increase allocations to 


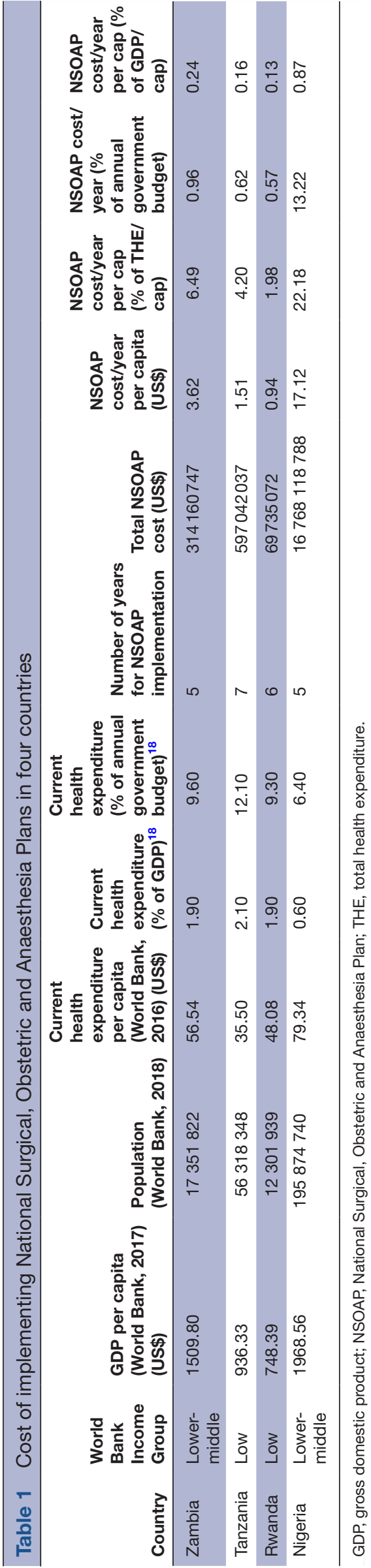

health, it is also likely that even with increased domestic funding for health, many LMICs, particularly low-income countries, may not be able to meet their health financing needs. Therefore, other means of fiscal space expansion, such as development assistance for health and innovative financing mechanisms, will still be needed. ${ }^{13-16}$

NSOAPs include a comprehensive set of interventions such as creating a specialised workforce which requires several years of training. For example, Tanzania's NSOAP aims to increase the physician surgeon, obstetrician and anaesthesiologist provider density from 0.46 per 100000 people to 2.27 per 100000 people by $2025 .{ }^{17}$ It should be noted that when Verguet and colleagues modelled costs for scaling up SOA care based on 2000-2013 data, they did not include training of surgical and anaesthesia providers and associated personnel. ${ }^{8}$ Hence, current NSOAPs provide updated and comprehensive cost estimates for scaling surgical systems addressing all pillars of the health system.

Scaling up surgical systems through NSOAPs is invariably an exercise in health systems strengthening. It is worth noting that the components of an NSOAP are cross-cutting and span all six pillars of the health system: service delivery, workforce, infrastructure and supplies, finance, governance and information management. SOA care delivery requires surgical and anaesthesia providers, and also requires qualified ancillary staff, a reliable blood bank, effective referral systems, a responsive supply chain system, functioning laboratory, radiotherapy and pathology and reliable information systems. Expanding fiscal space for NSOAPs will likely strengthen the entire health system to improve the diagnosis, treatment and management of non-communicable and communicable diseases. SOA care is not a competitor for scarce resources; it is a synergistic partner in healthcare delivery that will allow countries achieve the SDGs and UHC.

Cost estimates from the first countries to develop NSOAPs suggest that scaling up surgical systems may not be as expensive as previously suggested. ${ }^{8}$ A moderate expansion of fiscal space for health by governments with support from development partners could achieve surgical system goals, strengthen the entire health system and promote economic growth.

Twitter @desmondtanko, @CheLenReddy, @LinaRoas, @JohnMeara

Acknowledgements We are deeply grateful to Rachel Yorlets from the Program in Global Surgery and Social Change at Harvard Medical School for proofreading this manuscript.

Contributors All authors contributed equally.

Funding $L R$ is funded by the Ronda Stryker and William Johnston Global Surgery Fund. JGM is supported by a grant from the General Electric Foundation.

Competing interests None declared.

Patient consent for publication Not required.

Provenance and peer review Not commissioned; externally peer reviewed.

Data availability statement No additional data are available.

Open access This is an open access article distributed in accordance with the Creative Commons Attribution Non Commercial (CC BY-NC 4.0) license, which permits others to distribute, remix, adapt, build upon this work non-commercially, and license their derivative works on different terms, provided the original work is 
properly cited, appropriate credit is given, any changes made indicated, and the use is non-commercial. See: http://creativecommons.org/licenses/by-nc/4.0/.

\section{REFERENCES}

1. Meara JG, Leather AJM, Hagander L, et al. Global surgery 2030: evidence and solutions for achieving health, welfare, and economic development. Lancet 2015;386:569-624.

2. Shrime MG, Bickler SW, Alkire BC, et al. Global burden of surgica disease: an estimation from the provider perspective. Lancet Glob Health 2015;3 Suppl 2:S8-S9.

3. Bickler SN, Weiser TG, Kassebaum N, et al. Global burden of surgical conditions. In: Debas HT, Donkor P, Gawande A, et al, eds. Essential surgery: disease control priorities, third edition (volume 1). Washington (DC): The International Bank for Reconstruction and Development/The World Bank, 2015.

4. Farmer PE, Kim JY, Surgery KJY. Surgery and global health: a view from beyond the OR. World J Surg 2008;32:533-6.

5. Roa L, Jumbam DT, Makasa E, et al. Global surgery and the sustainable development goals. Br J Surg 2019;106:e44-52.

6. World Health Organization. WHA 68.15: Strengthening emergency and essential surgical care and anaesthesia as a component of universal health coverage [Internet], 2015. Available: http://apps. who.int/gb/ebwha/pdf_files/WHA68/A68_R15-en.pdf

7. WHO Director General Dr. Tedros Addressing the Global Surgery Community March 20, 2019-YouTube [Internet]. Available: https:// www.youtube.com/watch?v=P1XLthxQs7g [Accessed cited 14 Jun 2019].

8. Verguet S, Alkire BC, Bickler SW, et al. Timing and cost of scaling up surgical services in low-income and middle-income countries from 2012 to 2030: a modelling study. Lancet Glob Health 2015;3(Suppl 2):S28-S37.
9. Alkire BC, Shrime MG, Dare AJ, et al. Global economic consequences of selected surgical diseases: a modelling study. Lancet Glob Health 2015;3 Suppl 2:S21-S27.

10. A heavy burden: the productivity cost of illness in Africa [Internet] WHO Reg. Off. Afr. Available: https://www.afro.who.int/publications/ heavy-burden-productivity-cost-illness-africa [Accessed cited $7 \mathrm{Jul}$ 2019]

11. WHO. The Abuja Declaration and the plan of action. An extract from the African Summit on Roll Back Malaria [Internet]. WHO. Available: http://www.who.int/malaria/publications/atoz/whocdsrbm200346/ en/ [cited 14 Jul 2016].

12. Dieleman JL, Campbell M, Chapin A, et al. Future and potential spending on health 2015-40: development assistance for health, and government, prepaid private, and out-of-pocket health spending in 184 countries. Lancet 2017;389:2005-30.

13. Atun R, Silva S, Knaul FM. Innovative financing instruments for global health 2002-15: a systematic analysis. Lancet Glob Health 2017;5:e720-6.

14. Peters AW, Pyda J, Menon G, et al. The World Bank Group: innovative financing for health and opportunities for global surgery. Surgery 2019;165:263-72.

15. Koch R, Roa L, Pyda J, et al. The Bill \& Melinda Gates Foundation: an opportunity to lead innovation in global surgery. Surgery 2019;165:273-80.

16. Sonderman KA, Citron I, Albutt K, et al. USAID: current support for global surgery and implications of reform. Surgery 2018;164:1147-55

17. Citron I, Jumbam D, Dahm J, et al. Towards equitable surgical systems: development and outcomes of a national surgical, obstetric and anaesthesia plan in Tanzania. BMJ Glob Health 2019;4:e001282.

18. Micah AE, Chen CS, Zlavog BS, et al. Trends and drivers of government health spending in sub-Saharan Africa, 1995-2015. BMJ Glob Health 2019;4:e001159. 